\title{
Corrigendum: The Pathophysiology of Degenerative Cervical Myelopathy and the Physiology of Recovery Following Decompression
}

\begin{abstract}
Farhana Akter ${ }^{1,2,3 * t}$, Xinming Yu ${ }^{1 \dagger}$, Xingping Qin ${ }^{3}$, Shun Yao ${ }^{4}$, Parisa Nikrouz ${ }^{5}$, Yasir Ahmed Syed ${ }^{6,7}$ and Mark Kotter ${ }^{1}$

${ }^{1}$ Department of Clinical Neuroscience, University of Cambridge, Cambridge, United Kingdom, ${ }^{2}$ Faculty of Arts and Sciences, Harvard University, Cambridge, MA, United States, ${ }^{3}$ Massachusetts General Hospital Cancer Center, Harvard Medical School, Boston, MA, United States, ${ }^{4}$ Department of Neurosurgery, Brigham and Women's Hospital, Harvard Medical School, Boston, MA, United States, ${ }^{5}$ Maidstone and Tunbridge Wells Trust, Maidstone, United Kingdom, ${ }^{6}$ Neuroscience and Mental Health Research Institute (NMHRI), Cathays, United Kingdom, ${ }^{7}$ School of Bioscience, Cardiff University, The Sir Martin Evans Building, Cardiff, United Kingdom
\end{abstract}

Keywords: neuronal loss, apoptosis, pathogenesis, spine, degeneration

\section{A Corrigendum on}

The Pathophysiology of Degenerative Cervical Myelopathy and the Physiology of Recovery Following Decompression

by Akter, F., Yu, X., Qin, X., Yao, S., Nikrouz, P., Syed, Y. A., et al. (2020). Front. Neurosci. 14:138. doi: $10.3389 /$ fnins.2020.00138

In the published article, an author name was incorrect as Yasir Syed. The correct name is Yasir Ahmed Syed.

In the original article, we neglected to include the funder Cambridge NIHR Brain Injury MedTech Cooperative, NIHR Clinician Scientist Award CS-2015-15-023 to Mark Kotter. The updated Funding statement appears below.

\section{FUNDING}

We gratefully acknowledge support by the Cambridge NIHR Brain Injury MedTech Cooperative. MK was funded by a NIHR Clinician Scientist Award CS-2015-15-023.

\section{DISCLAIMER}

This report is independent research arising from a Clinician Scientist Award, CS-2015-15-023, supported by the National Institute for Health Research. The views expressed in this publication are those of the authors and not necessarily those of the NHS, the National Institute for Health Research or the Department of Health.

The authors apologize for these errors and state that this does not change the scientific conclusions of the article in any way. The original article has been updated.

Copyright $\odot 2020$ Akter, Yu, Qin, Yao, Nikrouz, Syed and Kotter. This is an open-access article distributed under the terms of the Creative Commons Attribution License (CC BY). The use, distribution or reproduction in other forums is permitted, provided the original author(s) and the copyright owner(s) are credited and that the original publication in this journal is cited, in accordance with accepted academic practice. No use, distribution or reproduction is permitted which does not comply with these terms. 